\title{
Positive effect of CPAP treatment on the control of difficult-to-treat hypertension
}

\author{
M.A. Martínez-García*, R. Gómez-Aldaraví" , J-J. Soler-Cataluña*, T.G. Martínez", \\ B. Bernácer-Alpera" and P. Román-Sánchez
}

ABSTRACT: The aim of the present study was to analyse the role of continuous positive airway pressure (CPAP) treatment in patients with difficult-to-control hypertension (DC-HT) and sleep apnoea.

An Autoset ${ }^{\mathrm{TM}}$ (ResMed, Sydney, Australia) study was performed in 60 patients diagnosed with DC-HT based on two 24-h ambulatory blood pressure monitorisation (ABPM) studies. CPAP was offered to patients with an apnoea/hypopnoea index $(A H I) \geqslant 15$ events $\cdot h^{-1}$. After 3 months of treatment, repeat ABPM was performed to evaluate the effect of CPAP upon the blood pressure values.

A total of 39 (65\%) patients received CPAP treatment, but only 33 completed the study. The mean \pm SD systolic and diastolic blood pressures (SBP and DBP, respectively) were $154.8 \pm 14$ and $90 \pm 8.8 \mathrm{mmHg}$. Patients had a mean \pm SD AHI of $37.7 \pm 18.2$ events $\cdot h^{-1}$. Only three patients presented a dipper nocturnal pressure pattern. CPAP treatment significantly reduced SBP $(-5.2 \mathrm{mmHg})$, and particularly the nocturnal values $(-6.1 \mathrm{mmHg})$, but not DBP. Considering only those patients who tolerated CPAP, the decrease in SBP was greater $(-7.3 \mathrm{mmHg})$. Furthermore, CPAP treatment significantly increased the percentage of patients who recovered the dipper pattern (three $(9.1 \%)$ out of 33 versus $12(36.4 \%)$ out of 33 ).

Continuous positive airway pressure treatment significantly reduces systolic blood pressure, particularly at night, and normalises the nocturnal pressure pattern in patients with difficult-tocontrol hypertension and sleep apnoea.

KEYWORDS: Ambulatory blood pressure monitorisation, continuous positive airway pressure, difficult-to-control hypertension, refractory hypertension, sleep apnoea

$\mathrm{t}$ is increasingly accepted that sleep apnoea/ hypopnoea syndrome (SAHS) is a risk factor for the development of systemic arterial hypertension (AHT) independently of other confounding variables, such as patient age, sex or obesity [1]. However, there is greater controversy over the role of SAHS in difficult-tocontrol hypertension (DC-HT). Some authors have reported a very high prevalence of SAHS in patients with uncontrolled AHT or an increased lack of AHT control in patients with SAHS [2-5].

Over $10 \%$ of all established hypertensive patients remain hypertensive despite the administration of three or more drugs with good adherence to therapy and after discarding other secondary AHT presentations [6, 7]. These cases are referred to as refractory hypertension or DC-HT [8]. These patients present a high incidence of cardiovascular events and thus represent an important healthcare problem [9]. According to some studies, the prevalence of SAHS among such individuals reaches $71-83 \%[4,5]$. It has been demonstrated that a decrease of only 5$10 \mathrm{mmHg}$ in systolic blood pressure (SBP) significantly reduces the incidence of new vascular events $[10,11]$. Few studies to date $[12,13]$ have analysed the role of continuous airway positive pressure (CPAP) treatment upon blood pressure control in hypertensive patients and only one [13] has analysed the role of CPAP in patients with refractory hypertension or DC-HT, although the number of patients involved was very limited.

The present study investigates the role of CPAP in blood pressure control among patients with SAHS and DC-HT.

\section{MATERIAL AND METHODS \\ Patients and protocol}

The present study recruited all patients with suspected DC-HT followed-up in the present authors' centre (Hospital General de Requena,
AFFILIATIONS

*Pneumology Unit,

${ }^{\#}$ Cardiology Unit, and

- Service of Internal Medicine,

Requena General Hospital, Valencia Spain.

CORRESPONDENCE

M.A. Martínez-García

Unidad de Neumología

Servicio de Medicina Interna Hospital General de Requena

Paraje Casa Blanca s/n

43230 Requena

Valencia

Spain

Fax: 34962336973

E-mail: med013413@nacom.es

Received:

April 082006

Accepted after revision:

January 162007

SUPPORT STATEMENT

The authors did not declare any conflict of interest and did not receive financial support or grant in the present study.

STATEMENT OF INTEREST None declared.

European Respiratory Journal Print ISSN 0903-1936 Online ISSN 1399-3003 
Valencia, Spain) during the course of 2004. DC-HT was suspected in patients with persistent SBP $\geqslant 140 \mathrm{mmHg}$ or diastolic blood pressure (DBP) $\geqslant 90 \mathrm{mmHg}$, as established by routine outpatient measurements, despite the use of at least three antihypertensive drugs at therapeutically effective doses (one being a diuretic in the absence of contraindications). The diagnosis of DC-HT was confirmed by two 24-h ambulatory blood pressure monitorisation (ABPM) studies spaced 15 days apart (i.e. ABPM-0 and -1 ), in view of the reported pressor effect associated with single ABPM studies [14]. Following international guidelines, DC-HT was confirmed by mean SBP and DBP values $\geqslant 125$ and $\geqslant 80 \mathrm{mmHg}$, respectively, in both ABPM studies during the 24-h registry period [15]. No changes were made to antihypertensive medication between the two ABPM studies. Exclusion criteria were: 1) previous treatment with CPAP; 2) secondary AHT; 3) current use of medication capable of altering blood pressure, such as nonsteroidal antiinflammatory drugs or systemic corticosteroids; and 4) poor treatment compliance. Secondary AHT was identified via application in all patients of a diagnostic protocol comprising: 1) abdominal ultrasound; 2) angio-computer axial tomography of the renal arteries; 3) thyroid hormone assay; 4) kidney function (patients with serum creatinine $>1.5 \mathrm{mg} \cdot \mathrm{dL}^{-1}$ were excluded from the study); and 5) catecholamine and cortisol determination in 24-h urine. Other special tests were performed in some patients according to the clinical criterion. Adherence to treatment was assessed with the Haynes-Sackett test, based on percentage compliance [16]. This test defines good adherence to treatment as the consumption of $\geqslant 80 \%$ of the prescribed medication during the last month of prescription. The combined antihypertensive treatment received by patients was based on international recommendations [15]. General and anthropometric data were collected on all patients (body mass index (BMI) and neck circumference) together with the clinical characteristics associated with SAHS; i.e. chronic snoring disorder, witnessed apnoeas, diurnal hypersomnia quantified by the Epworth Sleepiness Scale (ESS), and the use of antihypertensive medication or any other drugs capable of interfering with blood pressure values. The study was approved by the local ethics committee and all patients gave informed consent to participate.

\section{4-h ABPM}

The ABPM studies (Marquette, Tonoport V; GE Medical Systems IT Inc., Milwakee, WI, USA) were carried out by measuring blood pressure with a cuff adapted to the arm circumference of the patient during an interval of $20 \mathrm{~min}$ during the day and $30 \mathrm{~min}$ at night. The following parameters were analysed: 1) mean diurnal and nocturnal SBP; 2) mean diurnal and nocturnal DBP; and 3) cardiac frequency. The number of patients with dipper and nondipper nocturnal blood pressure patterns was also determined. Dippers were defined as those patients presenting a minimum mean nocturnal SBP decrease of $10 \%$ with respect to the mean diurnal SBP value. The diurnal and nocturnal pressure measurement periods were determined by instructing the patients to record the approximate times at which they fell asleep and awakened, respectively, on the days of the ABPM studies.

\section{Sleep study}

In all patients with confirmed DC-HT who met the required inclusion and exclusion criteria, a nonattended nocturnal evaluation was carried out using the Autoset ${ }^{\mathrm{TM}}$ (AS) portable plus II system (ResMed, Sydney, Australia) within a maximum of 15 days after the ABPM- 1 study. The AS is an auto-CPAP model in which the diagnostic mode allows the recording of different respiratory variables and patient's cardiac frequency. The system has been described and validated by several studies [17-20]. The AS provided a semi-quantitative reading of nasal ventilation. Respiratory events and apnoea/hypopnoea index (AHI) have been defined by the present authors' group elsewhere [21]. All data were calculated as a function of the total recording time. Tests in which the patient claimed to have slept for $\geqslant 4 \mathrm{~h}$ were considered valid. Tests involving some technical malfunction or patient-caused disconnection resulting in $<4 \mathrm{~h}$ of valid recording were regarded as invalid and the AS study was repeated.

\section{CPAP treatment and follow-up}

CPAP treatment was offered to patients with AHI $\geqslant 15$ events $\cdot h^{-1}$. The empirical initial CPAP was calculated for each patient using a published prediction formula based on anthropometric parameters and AHI [22]. This pressure was maintained for 1 month of initial adaptation until automatic CPAP titration with AS was carried out. During this time, contact was maintained with the patient to solve any possible problems and side-effects (particularly leakage problems), ensuring an appropriate nonleaking mask. Low-leak 95thpercentile pressure was used. In the event of a severe leak $\left(>0.4 \mathrm{~L} \cdot \mathrm{s}^{-1}\right)$, the titration was considered invalid and the test was repeated. Only tests in which the patient claimed to have slept for $\geqslant 3 \mathrm{~h}$ and where $\geqslant 4 \mathrm{~h}$ of recording were available were considered valid. Acceptable compliance was considered if the patient used CPAP for $\geqslant 4 \mathrm{~h}$ at night, during $\geqslant 75 \%$ of nights. After 2 months of CPAP treatment counting from the date of automatic pressure titration, a new ABPM study was performed (ABPM-2) to evaluate the effect of CPAP treatment upon the pressure values.

\section{Statistical analysis}

Quantitative variables were expressed as mean $\pm \mathrm{SD}$, while qualitative variables were reported as absolute values and percentages. Normal distribution of the variables was confirmed with the Kolmogorov-Smirnov test. The comparison of two means was based on unpaired and paired t-tests for independent (inter-group comparisons) and dependent variables (intra-group comparisons), respectively. For the comparison of two qualitative variables with repeated measures the McNemar test was used. The Spearman test was used to calculate the correlation between two quantitative variables. Calculation was made of the sample size for assessing a minimum reduction of $5 \mathrm{mmHg}$ in SBP after CPAP treatment, assuming an $\alpha$-error of $5 \%$ and a statistical power of $80 \%$. The resulting sample size was 21 patients. Intention-to-treat (ITT) analysis was used to explore the effect of CPAP in all patients who were offered such treatment (whether tolerated or not) and who completed the study (involving three ABPM studies). A parallel analysis was also made involving only those patients who tolerated CPAP treatment. A p-value $<0.05$ was considered statistically significant. 


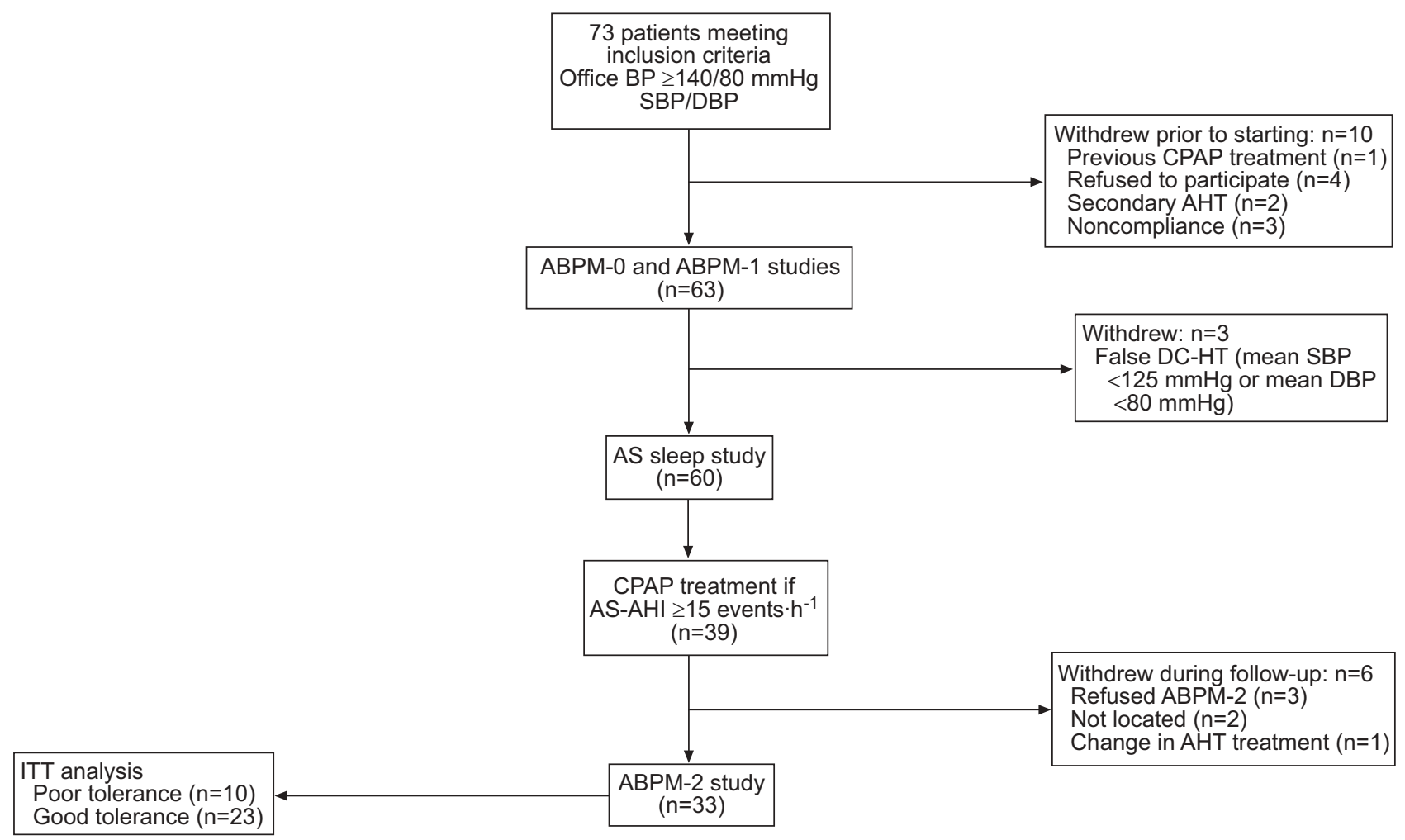

FIGURE 1. Study protocol flowchart. BP: blood pressure; SBP: systolic blood pressure; DBP: diastolic blood pressure; CPAP: continuous positive airway pressure; ABPM: 24-h ambulatory blood pressure monitorisation; AHT: arterial hypertension; DC-HT: difficult-to-control arterial hypertension; AS: Autoset ${ }^{\mathrm{TM}}$ (ResMed, Sydney, Australia); AS-AHI: Autoset ${ }^{\mathrm{TM}}$-apnoea/hypopnoea index; ITT: intention-to-treat.

\section{RESULTS}

The study initially included a total of 73 patients with suspected DC-HT according to the routine outpatient pressure findings (SBP $\geqslant 140 \mathrm{mmHg}$ and/or DBP $\geqslant 90 \mathrm{mmHg}$ ). Figure 1 shows the patients who were excluded in the course of the study. Both initial ABPM studies (ABPM-0 and -1) were conducted in 63 patients. There were no significant differences between the mean SBP or DBP values between ABPM-0 and -1 (mean differences 1.9 and $1.1 \mathrm{mmHg}$, respectively). DC-HT was not confirmed in three patients. Out of the 60 patients subjected to AS study, 39 (65\%) presented AHI $\geqslant 15$ events $\cdot h^{-1}$. During the month of initial adjustment with a mean \pm SD (range) pressure of $6.9 \pm 2.4$ (5-13) $\mathrm{cmH}_{2} \mathrm{O}$, calculated from the mathematical formula, 10 patients either failed to tolerate or rejected CPAP treatment despite several attempts. Thus, automatic pressure titration was carried out in 29 patients (mean \pm SD (range) pressure $7.4 \pm 2.8(6-14) \mathrm{cmH}_{2} \mathrm{O}$ ), without significant differences versus the mathematically calculated pressure $(p=0.44)$. During the subsequent 2 months of CPAP treatment, all patients tolerated the treatment with a mean \pm SD (range) of $5.9 \pm 2.7$ (48.5) $\mathrm{h} \cdot$ night $^{-1}$. Six patients were excluded: three patients in whom the ABPM-2 study was not performed; two patients who could not be located; and one patient who increased the antihypertensive treatment. Thus, a total of 33 patients ( 23 with good tolerance of CPAP until the end of the study and 10 patients with poor tolerance or rejection of CPAP treatment) completed ABPM-2 and finished the study. The characteristics of the patients considered globally and according to tolerance of CPAP treatment are reported in table 1. Diuretics were used in all patients except where withdrawal was required due to sideeffects or contraindication. The most common drug combination was a diuretic plus an angiotensin-receptor blocker plus a calcium antagonist. There were no significant differences between the antihypertensive regimen used by the group that tolerated CPAP and the group that failed to tolerate CPAP (table 2). Likewise, there were no significant differences for the different combinations of three or more possible antihypertensive drugs prescribed (data not shown).

\section{ITT analysis}

As can be seen in table 3, on including in the analysis all patients who were offered CPAP and finished the study, significant decreases were recorded in mean $24-\mathrm{h}(-5.2 \mathrm{mmHg}$; $\mathrm{p}=0.01)$, mean diurnal $(-4.2 \mathrm{mmHg} ; \mathrm{p}=0.02)$ and mean nocturnal $(-6.1 \mathrm{mmHg} ; \mathrm{p}=0.01)$ SBP without significant changes in DBP. Conversely, the number of patients that recovered the dipper nocturnal pressure pattern after CPAP treatment increased significantly both on analysing the group that tolerated CPAP (two $(8.7 \%$ ) out of 23 patients pre-CPAP versus $11(47.8 \%)$ out of 23 patients post-CPAP; $\mathrm{p}=0.002)$ and on performing the ITT analysis (three $(9.1 \%)$ out of 33 patients versus $12(36.4 \%)$ out of 33 patients; $\mathrm{p}=0.004)$. However, there were no significant differences in the number of patients with dipper patterns among those who failed to tolerate CPAP. There were no significant modifications in antihypertensive treatment, BMI or cardiac frequency. There was no correlation between the number of hours of CPAP and the magnitude of the DBP change $(\mathrm{r}=0.11 ; \mathrm{p}>0.05)$. 


\begin{tabular}{|c|c|c|c|c|}
\hline & \multirow[t]{2}{*}{ All patients } & \multicolumn{2}{|c|}{ CPAP treatment } & \multirow[t]{2}{*}{ p-value } \\
\hline & & Tolerated & Nontolerated & \\
\hline Subjects $n$ & 33 & 23 & 10 & \\
\hline Age yrs & $70.2 \pm 7.5$ & $68.1 \pm 7.8$ & $72.2 \pm 3.2$ & NS \\
\hline Sex male & $17(52)$ & $12(52.2)$ & $5(50)$ & NS \\
\hline BMI $\mathbf{k g} \cdot \mathrm{m}^{-2}$ & $34.2 \pm 5$ & $35.1 \pm 5.2$ & $33.2 \pm 4.7$ & NS \\
\hline $\begin{array}{l}\text { Neck circumference } \\
\mathrm{cm}\end{array}$ & $41.6 \pm 4.9$ & $42.6 \pm 4.6$ & $40.6 \pm 5.6$ & NS \\
\hline ESS & $6.3 \pm 4.5$ & $7.4 \pm 5.1$ & $5.1 \pm 1.3$ & NS \\
\hline Chronic snoring & $18(54.5)$ & $13(56.5)$ & $5(50)$ & NS \\
\hline Number of drugs & $3.64 \pm 0.7$ & $3.5 \pm 0.7$ & $3.7 \pm 0.8$ & NS \\
\hline Witnessed apnoeas & $7(21)$ & $5(21.7)$ & $2(20)$ & NS \\
\hline AS-AHI $h^{-1}$ & $37.7 \pm 18.2$ & $40 \pm 19.7$ & $35.4 \pm 14.3$ & NS \\
\hline CT90\% & $10.4 \pm 5.7$ & $11.3 \pm 5.3$ & $9.4 \pm 5.8$ & NS \\
\hline $\begin{array}{l}\text { Mean 24-h SBP } \\
\text { mmHg }\end{array}$ & $154.8 \pm 14$ & $155.1 \pm 15.4$ & $153.9 \pm 10.3$ & NS \\
\hline $\begin{array}{l}\text { Mean 24-h DBP } \\
\text { mmHg }\end{array}$ & $90 \pm 8.8$ & $90.5 \pm 9.8$ & $88.8 \pm 5.8$ & NS \\
\hline Dippers & $3(9.1)$ & $2(8.7)$ & $1(10)$ & NS \\
\hline $\begin{array}{l}\text { Cardiac frequency } \\
\text { beats } \cdot \mathrm{min}^{-1}\end{array}$ & $73 \pm 13$ & $74.2 \pm 12.3$ & $72.7 \pm 13.4$ & NS \\
\hline
\end{tabular}

Data are presented as mean $\pm S D$ or $n(\%)$, unless otherwise stated. CPAP: continuous positive airway pressure; BMI: body mass index; ESS: Epworth

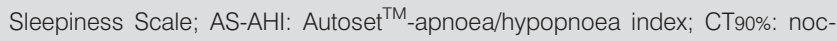
turnal counting time with an oxygen saturation $<90 \%$; SBP: systolic blood pressure; DBP: diastolic blood pressure; NS: nonsignificant.

\section{Analysis according to CPAP tolerance}

Table 4 shows the analysis performed according to tolerance or nontolerance of CPAP for $\geqslant 4 \mathrm{~h} \cdot \mathrm{day}^{-1}$. Patients who tolerated CPAP $(n=23)$ showed a drop in mean $24-h$ SBP of $-7.6 \mathrm{mmHg}$ $(-6.5 \mathrm{mmHg}$ diurnal and $-8.7 \mathrm{mmHg}$ nocturnal), without significant changes in DBP. However, there were no significant changes in either mean diurnal or nocturnal SBP or DBP among the patients who did not tolerate CPAP $(n=10)$. There were no significant changes in antihypertensive medication or BMI in either patient group during the course of the study.

\section{DISCUSSION}

According to the present results, CPAP treatment during 3 months induced a significant decrease in mean diurnal and fundamentally nocturnal SBP among patients with DC-HT and excessive sleep-disordered breathing (SDB). This in turn led to a significant increase in the number of patients who recovered the normal nocturnal dipper blood pressure pattern. CPAP treatment was well tolerated by most subjects.

The existing evidence tends to confirm the existence of a linear relationship between the severity of SAHS and an excess prevalence of SDB $[23,24]$. Increased controversy focuses on whether the presence of excessive SDB can lead to an increased lack of blood pressure control [2-5], or whether CPAP treatment can cause the pressure values to decrease significantly [12, 25-28]. Although some studies have confirmed such a decrease, most comprised mainly normotensive patients
TABLE 2 Use of prescribed antihypertensive medication

\begin{tabular}{|c|c|c|c|c|}
\hline & \multirow[t]{2}{*}{ All patients } & \multicolumn{2}{|c|}{ CPAP treatment } & \multirow[t]{2}{*}{ p-value } \\
\hline & & Tolerated & Nontolerated & \\
\hline Subjects n & 33 & 23 & 10 & \\
\hline Diuretics & $31(94)$ & 21 (91.3) & $10(100)$ & NS \\
\hline AT-r blockers & $23(69.7)$ & $16(69.6)$ & $7(70)$ & NS \\
\hline Ca-antagonists & $22(66.7)$ & $15(65.2)$ & $7(70)$ & NS \\
\hline$\beta$-blockers & $18(54.5)$ & $12(52.2)$ & $6(60)$ & NS \\
\hline$\alpha$-blockers & $15(42.4)$ & $11(47.8)$ & $4(40)$ & NS \\
\hline ACE inhibitor & $10(30.3)$ & $7(30.4)$ & $3(30)$ & NS \\
\hline Other & $1(3)$ & $1(4.3)$ & $0(0)$ & NS \\
\hline \multicolumn{5}{|c|}{$\begin{array}{l}\text { Data are presented as } n(\%) \text {, unless otherwise stated. CPAP: continuous } \\
\text { positive airway pressure; AT-r: angiotensin receptor; Ca: calcium; ACE: } \\
\text { angiotensin-converting enzyme; NS: nonsignificant. }\end{array}$} \\
\hline
\end{tabular}

referred to a sleep clinic [25, 26, 28]. LoGAN et al. [13], in the only study to date conducted in patients with refractory AHT, reported a decrease of 11 and $7.8 \mathrm{mmHg}$ in SBP and DBP, respectively, particularly during the nocturnal hours after 2 months of CPAP treatment. However, the small number of patients involved $(n=11)$ did not afford sufficient statistical power for the drawing of firm conclusions. In this sense, the current study presents two interesting aspects: 1) it involves only patients referred to an AHT unit where two ABPM studies confirmed DC-HT; and 2) the number of patients analysed exceeds the minimum sample size required $(n=21)$ to achieve a drop $\geqslant 5 \mathrm{mmHg}$ in SBP with CPAP treatment for both ITT analysis $(n=33)$ and for the analysis of only those patients who tolerated CPAP $(n=23)$. This guaranteed the necessary statistical power. It is important to mention that six patients in whom ABPM-2 was not carried out were excluded from the ITT analysis, as a result of which the latter was not strictly an ITT analysis. The best way to deal with the data of these patients in an ITT analysis remains open to controversy (i.e. elimination from the study, substitution of the missing data, selection of the worst case scenario for the results of these patients, etc.) [29]. It was decided to exclude these subjects from the study since they were few in number and the present authors felt that their exclusion would not affect the conclusions drawn. The present results coincide in part with those reported by LOGAN et al. [13]. Both studies found a significant decrease in SBP, particularly at night, with CPAP treatment. However, no statistically significant differences were observed in $\mathrm{DBP}$, despite the recording of a $2.5-\mathrm{mmHg}$ drop in mean nocturnal DBP among the patients who tolerated CPAP. This could be because no calculation was made of sample size in relation to the expectable changes in DBP. In this sense, a type II error may have been introduced with the impossibility of identifying existing significant differences in DBP. In any case, the decrease in DBP observed in the present study, while moderate, may have positive long-term effects in terms of cardiovascular morbidity or mortality.

Participant patients with DC-HT showed a series of characteristics associated with very high vascular risk. In effect, they showed an important lack of blood pressure control despite 


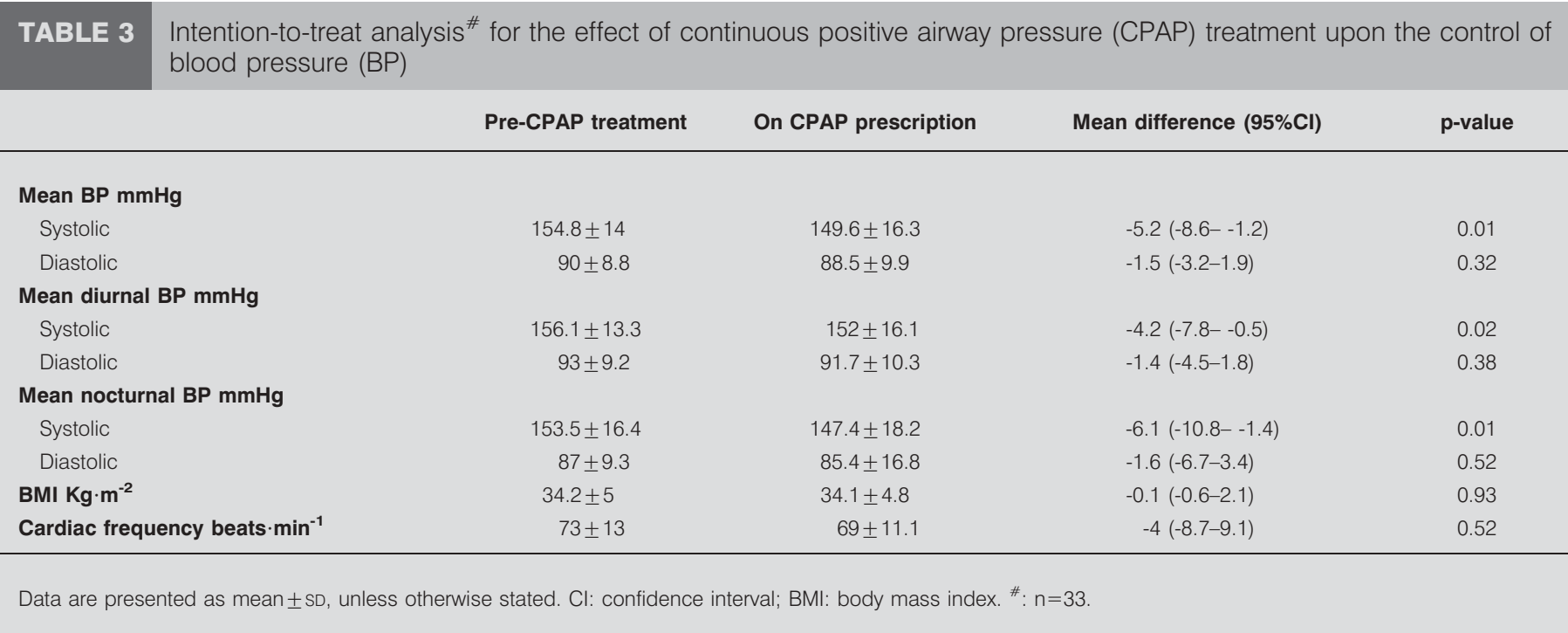

antihypertensive treatment, with mean 24-h SBP and DBP values of 154.8 and $90 \mathrm{mmHg}$, respectively. Furthermore, there was an important presence of SDB (mean AHI 37.7 events $\cdot h^{-1}$ ). In this sense, some studies have observed increases in the incidence of new cardiovascular events $[21,30]$ and general [31] or cardiovascular mortality [32] in patients with excessive SDB, which appear to increase during the nocturnal hours [33]. Lastly, patients also presented a loss of normal nocturnal dipper pressure pattern (only three subjects exhibited dipper patterns in the present study). This phenomenon appears to add to the increased vascular risk in such patients [34]. Considering this, it could be postulated that the correction or improvement of some of these risk factors may reduce the incidence of cardiovascular morbidity-mortality. In this sense, the present study suggests that CPAP treatment could exert an important preventive effect against new vascular events summarised by the following observations. 1) Normalisation of the number of SDB (AHI 37.7 events $\cdot \mathrm{h}^{-1}$ pre-CPAP versus 3.8 post-CPAP). 2) A decrease of $\sim 5 \mathrm{mmHg}$ in mean $24-\mathrm{h}$ SBP ( $8 \mathrm{mmHg}$ when considering only the patients who tolerated CPAP), when a decrease of $5-10 \mathrm{mmHg}$ in SBP is known to significantly reduce the incidence of new vascular events (20$50 \%$ at $3-5$ yrs) $[10,11] .3)$ The drop in SBP among patients was fundamentally nocturnal and reached $\sim 9 \mathrm{mmHg}$ in those who tolerated CPAP. It has been suggested that nocturnal SBP is a better predictor of new vascular events than the diurnal pressure value [35]. 4) A significant number of CPAP-treated patients recovered their physiological nocturnal dipper pressure pattern. This interesting observation could be explained both by the normalisation of SDB after CPAP treatment, since

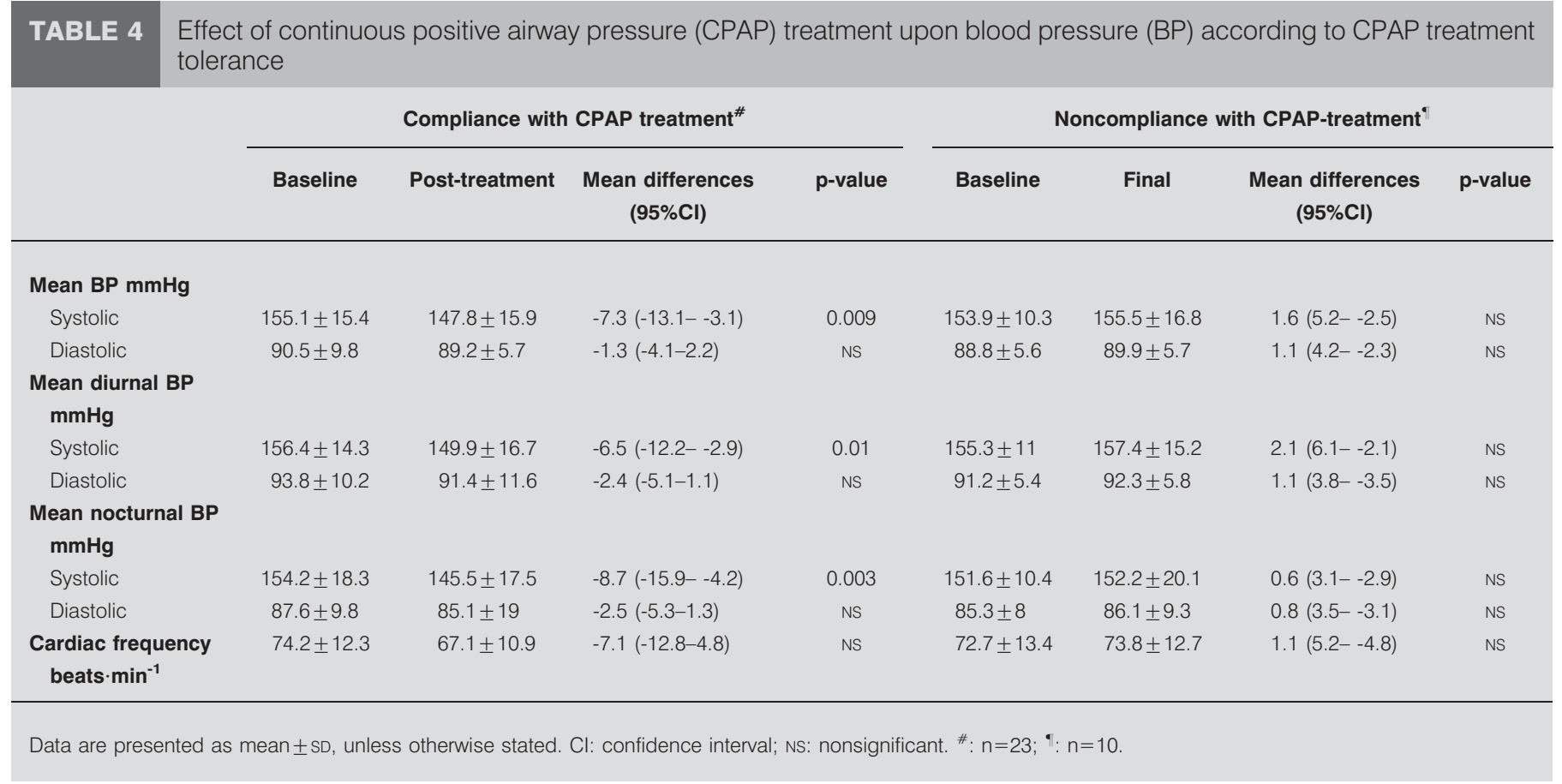


SAHS is a known cause of nondipper pressure patterns, and by the increased drop in nocturnal versus diurnal pressure values with such treatment, since a large percentage of DC-HT patients have been shown to present nocturnal nondipper patterns [36-38].

Conversely, CPAP treatment was well tolerated in the present study $(>70 \%)$, with tolerance figures similar to those reported for patients with SAHS [39]. No significant differences were observed in the characteristics of the two groups (i.e. patients with good versus poor tolerance) and, as a result, the present authors were unable to predict a nontolerant patient profile. In any case, it is important to state that patients who tolerated CPAP treatment showed a greater tendency towards obesity, with increased hypersomnia and a greater number of breathing disorders during sleep. In this sense, and considering that the number of patients included in the study was small, it cannot be discarded that unintentional selection bias may have affected the present conclusions.

It is noteworthy that the current patients generally presented a low pre-test clinical probability of SAHS. In the present study, $<55 \%$ of the patient population reported chronic snoring and only $18 \%$ presented an ESS score of $>10$. This observation supports the need for sleep studies in all patients with DC-HT, regardless of the clinical characteristics of the existing SAHS.

The present study has a series of limitations. First, the AS system does not allow quantification of the hours of sleep and it has not been validated in populations with a low pre-test probability of suffering obstructive sleep apnoea syndrome. In any case, the studies that have validated this technique versus polysomnography report that the AS system offers good correlation values in patients with a high AHI cut-off point, even with a low ESS score value, as is the case in the current population [18-20]. Secondly, a nonrandomised placebo controlled trial was used in an attempt to maximise the number of patients receiving effective CPAP treatment and exceeding the estimated sample size, as the percentage of patients with truly refractory AHT was small. In any case, the present authors are aware of the loss of scientific evidence this decision implies. Despite the limitations of the study, it is believed that in the present longitudinal survey (before versus after CPAP treatment), in which the study group serves as its own control, the observed reductions in SBP are unlikely to be attributable to chance, particularly when considering that no significant pressure changes were recorded in the patients who failed to tolerate CPAP or in whom the latter was not indicated.

In conclusion, continuous positive airway pressure treatment in patients with difficult-to-control hypertension and excessive sleep-disordered breathing yielded a significant reduction in diurnal and particularly nocturnal systolic blood pressure, with no significant variations in diastolic blood pressure. This led to an increase in the number of patients who recovered their normal nocturnal dipper pressure pattern. Continuous positive airway pressure treatment was well tolerated by these patients, despite the scant clinical manifestations of sleep apnoea/hypopnoea syndrome. The present authors consider that sleep studies are indicated in all patients with difficult-tocontrol hypertension of unknown origin, regardless of the clinical manifestations of sleep apnoea/hypopnoea syndrome.
Lastly, larger studies are needed to confirm the present results and analyse the foreseeable positive effects of long-term continuous positive airway pressure treatment upon cardiovascular morbidity and mortality in the current group of patients.

\section{REFERENCES}

1 Peppard PE, Young T, Palta M, Skatrud J. Prospective study of the association between sleep-disordered breathing and hypertension. N Engl J Med 2000; 342: 1378-1384.

2 Lavie P, Hofftein V. Sleep apnea syndrome: a possible contributing factor to resistant hypertension. Sleep 2001; 24: 721-725.

3 Grote L, Hedner J, Peter JH. Sleep-related breathing disorder is an independent risk factor for uncontrolled hypertension. J Hypertens 2000; 18: 679-685.

4 Logan AG, Perlikowski SM, Mente A, et al. High prevalence of unrecognized sleep apnea in drug-resistant hypertension. J Hypertens 2001; 19: 2271-2277.

5 Martínez-García MA, Gómez-Aldaraví R, Gil-Martínez T, Soler-Cataluña JJ, Bernácer-Alpera B, Román-Sánchez P. Trastornos respiratorios durante el sueño en pacientes con hipertensión arterial de difícil control. [Sleep-disordered breathing in patients with difficult-to-control hypertension.] Arch Bronconeumol 2006; 42: 14-20.

6 Meissner I, Whisnant JP, Sheps SG, et al. Detection and control of high blood pressure in the community: do we need a wake-up call? Hypertension 1999; 34: 466-471.

7 Berlowitz DR, Ash AS, Hickey EC, et al. Inadequate management of blood pressure in a hypertensive population. N Engl J Med 1998; 339: 1957-1963.

8 Setaro JF, Black HR. Refractory hypertension. N Engl J Med 1992; 327: 543-547.

9 Isaksson H, Östergren J. Prognosis in therapy-resistant hypertension. J Intern Med 1994; 236: 643-649.

10 Turnbull F, Blood Pressure Lowering Treatment Trialists' Collaboration. Effects of different blood-pressure-lowering regimens on major cardiovascular events: results of prospectively-designed overviews of randomised trials. Lancet 2003; 362: 1527-1535.

11 Rodgers A, Neal B, MacMahon S. The effects of blood pressure lowering in cerebrovascular disease. Neurol Rev Int 1997; 2: 2-15.

12 Hla KM, Skatrud JB, Finn L, Palta M, Young T. The effect of correction of sleep-disordered breathing on BP in untreated hypertension. Chest 2002; 122: 1125-1132.

13 Logan AG, Tkacova R, Perlikowski SM, et al. Refractory hypertension and sleep apnoea: effect of CPAP on blood pressure and baroreflex. Eur Respir J 2003; 21: 241-247.

14 Hermida RC, Zamarrón C, Ayala DE, Calvo C. Effect of continuous positive airway pressure on ambulatory blood pressure in patients with obstructive sleep apnoea. Blood Press Monit 2004; 9: 193-202.

15 European Society of Hypertension-European Society of Cardiology Guidelines Committee. 2003 European Society of Hypertension-European Society of Cardiology guidelines for the management of arterial hypertension. $J$ Hypertens 2003; 21: 1011-1053. 
16 Sackett DL, Haynes RB, Gibson ES, et al. Randomised clinical trial of strategies for improving medication compliance in primary hypertension. Lancet 1975; 1: 1205-1207.

17 Kiely JL, Delahunty C, Matthews S, McNicholas WT. Comparison of a limited computerized diagnostic system (ResCare Autoset) with polysomnography in the diagnosis of obstructive sleep apnoea syndrome. Eur Respir J 1996; 9: 2360-2364.

18 Gugger M. Comparison of ResMed AutoSet (version 3.03) with polysomnography in the diagnosis of the sleep apnoea/ hypopnoea syndrome. Eur Respir J 1997; 10: 587-591.

19 Fleury B, Rakotonanahary D, Hausser-Hauw C, Lebeau B, Guilleminault C. A laboratory validation study of the diagnostic mode of the Autoset system for sleep-related respiratory disorders. Sleep 1996; 19: 502-505.

20 Mayer P, Meurice JC, Philip-Joet F, et al. Simultaneous laboratory-based comparison of ResMed Autoset ${ }^{\mathrm{TM}}$ with polysomnography in the diagnosis of sleep apnoea/ hypopnoea syndrome. Eur Respir J 1998; 12: 770-775.

21 Martínez-García MA, Galiano-Blancart R, Román-Sánchez P, Soler-Cataluña JJ, Cabero-Salt L, Salcedo-Maiques E. Continuous positive airway pressure treatment in sleep apnea prevents new vascular events after ischemic stroke. Chest 2005; 128: 2123-2129.

22 Oliver Z, Hoffstein V. Predicting effective continuous positive airway pressure. Chest 2000; 117: 1061-1064.

23 Nieto FJ, Young T, Lind BK, et al. Association of sleepdisordered breathing, sleep apnea and hypertension in a large community-based study. Sleep Heart Health Study. JAMA 2000; 283: 1829-1836.

24 Young T, Peppard P, Palta M, et al. Population-based study of sleep-disordered breathing as a risk factor for hypertension. Arch Intern Med 1997; 157: 1746-1752.

25 Pepperell JC, Ramdassingh-Dow S, Crosthwaite N, et al. Ambulatory blood pressure after therapeutic and subtherapeutic nasal continuous positive airway pressure for obstructive sleep apnoea: a randomised parallel trial. Lancet 2002; 359: 204-210.

26 Faccenda JF, Mackay TW, Boon NA, Douglas NJ. Randomized placebo-controlled trial of continuous positive airway pressure on blood pressure in the sleep apneahypopnea syndrome. Am J Respir Crit Care Med 2001; 163: 344-348.

27 Barbé F, Mayoralas LR, Durán J, et al. Treatment with continuous positive airway pressure is not effective in patients with sleep apnea but no daytime sleepiness: a randomized, controlled trial. Ann Intern Med 2001; 134: 1015-1023.

28 Becker HF, Jerrentrup A, Ploch T, et al. Effect of nasal continuous positive airway pressure treatment on blood pressure in patients with obstructive sleep apnea. Circulation 2003; 107: 68-73.

29 Heritier SR, Gebski VJ, Keech AC. Inclusion of patients in clinical trial analysis: the intention-to-treat principle. Med J Aust 2003; 179: 438-440.

30 Marín JM, Carrizo SJ, Vicente E, Agustí AG. Long-term cardiovascular outcomes in men with obstructive sleep apnoea-hypopnoea with or without treatment with continuous positive airway pressure: an observational study. Lancet 2005; 365: 1046-1053.

31 Lavie P, Lavie L, Herer P. All-cause mortality in males with sleep apnoea syndrome: declining mortality rates with age. Eur Respir J 2005; 25: 514-520.

32 Parra O, Arboix A, Montserrat JM, Quinto L, Bechich S, García-Eroles L. Sleep-related breathing disorders: impact on mortality of cerebrovascular disease. Eur Respir J 2004; 24: $267-272$.

33 Gami AS, Howard DE, Olson EJ, Somers VK. Day-night pattern of sudden death in obstructive sleep apnea. $N$ Engl J Med 2005; 352: 1206-1214.

34 Verdecchia P, Porcelati C, Schillaci G, et al. Ambulatory blood pressure. An independent predictor of prognosis in essential hypertension. Hypertension 1994; 24: 793-801.

35 Staessen JA, Thijs L, Fagard R, et al. Predicting cardiovascular risk using conventional versus ambulatory blood pressure in older patients with systolic hypertension. Systolic Hypertension in Europe Trial Investigators. JAMA 1999; 282: 539-546.

36 Suzuki M, Guilleminault C, Otsuka K, Shiomi T. Blood pressure "dipping" and "non-dipping" in obstructive sleep apnea syndrome patients. Sleep 1996; 19: 382-387.

37 Akashiba T, Minemura $\mathrm{H}$, Yamamoto $\mathrm{H}$, Kosaka N, Saito O, Horie T. Nasal continuous positive airway pressure changes blood pressure "non-dippers" to "dippers" in patients with obstructive sleep apnea. Sleep 1999; 22: 849-853.

38 Redon J, Campos C, Narciso ML, Rodicio JL, Pascual JM, Ruilope LM. Prognostic value of ambulatory blood pressure monitoring in refractory hypertension: a prospective study. Hypertension 1998; 31: 712-718.

39 Rauscher H, Popp W, Wanke T, Zwick H. Acceptance of CPAP therapy for sleep apnea. Chest 1991; 100: 1019-1023. 